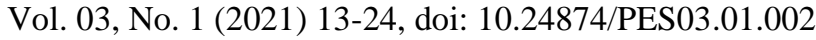 \\ Proceedings on Engineering Sciences
}

\section{OVERVIEW OF CORROSION AND ITS CONTROL: A CRITICAL REVIEW}

\author{
S. Harsimran \\ K. Santosh ${ }^{1}$ \\ K. Rakesh
}

Keywords:

Corrosion; Types, Erosion; Effect, Mechanism; Control.
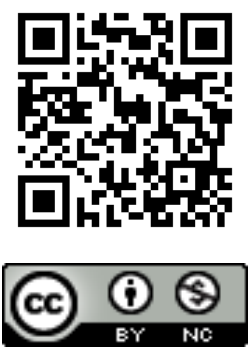

A B S T R A C T

Corrosion is the degradation of materials usually metal owing to chemical reaction with the environment which result in a functional failure of component. Corrosion is a reverse extractive metallurgy, which depends on the concentration of environment, stress, erosion and the temperature. It causes major economic losses ranges from 1\% to 5\% of GNP per year for any nations. In addition, corrosion not only increases the costs of component but it also responsible for life losses and safety hazard. Hence, the aim of this review paper is to provide an overview of distinct types of corrosion and their preventive method. So, that corrective action may be taken to minimize the effect of corrosion related problems.

(C) 2021 Published by Faculty of Engineering

\section{INTRODUCTION}

Corrosion is an irreversible damage of metal surface due to chemical reactions which results in conversion of a pure metal to its chemically more stable form such as sulphides, oxides, hydroxides, etc. in a corrosive environment. The corrosive environment may be of any type i.e. may be solid, liquid or gas. Corrosion is generally viewed as a universal phenomenon (Fernandes \& Monternor, 2015). These environments are generally known as electrolytes. These electrolytes allow the transfer of ions (cations and anions) and form two reactions (anodic and cathodic). If suppose, we have two different types of metals in a given electrolyte, then the less noble metal acts as anode and gets corroded whereas the more noble metal acts as cathode and gets protected. The electron flow is from anodic metal to cathodic metal. Among the two different metals present in a given environment, the metal with higher reduction potential (having higher position in electrochemical series) or less noble metal gets corroded. For example: $\mathrm{Cu}$ and $\mathrm{Zn}$ in a conducting solution. $\mathrm{Zn}$ has higher reduction potential than $\mathrm{Cu}$ so $\mathrm{Zn}$ acts as anode and gets corroded, whereas $\mathrm{Cu}$ acts as cathode and is protected. The electron flow is from $\mathrm{Zn}$ (less noble) to $\mathrm{Cu}$ (more noble). Loss of electrons takes place at anode (it is known as oxidation) while, the gain of electrons takes place at cathode (it is known as reduction). Corrosion damages the entire surface when most or all the metal particles on its surface get oxidized. Rusting of iron is the most common example of corrosion. Rust is hydrated ferric oxide $\left[\mathrm{Fe}_{2} \mathrm{O}_{3} \cdot \mathrm{xH}_{2} \mathrm{O}\right]$. Corrosion is a surface phenomenon i.e. it occurs at the surface of the materials. Corrosion takes place in several forms. First, an overall surface attack slowly reduces the thickness of the metal. Secondly, instead of an overall surface attack, only isolated areas are affected. Third, it also occurs along the grain boundaries or other lines of weakness because of a difference in resistance to corrosive environment (Singh, 1995). It is a slow process that damages industrial machines, metallic equipment, and reduces the overall value of that product. On annual basis, total economic loss due to various types of corrosions in India is nearly US\$6500 million. In the

\footnotetext{
1 Corresponding author: Santosh Kumar,
}

E- mail: santoshdgc@gmail.com 
US, total direct wastage is estimated about $3.2 \%$ of domestic product (Kumar et al. 2018). The key to control the corrosion is its proper awareness and by adapting suitable and timely measures (Palanisamy, 2019).

\section{CAUSE OF CORROSION}

Most of the metals found in nature are in the form of their compounds except the noble metals such as gold and platinum. This is due to the fact that the metals in their compound state are thermodynamically more stable than their elemental state (Vedavyasan, 2013). As most of the metals exists in the form of oxides so during their extraction into free state, a lot of energy is provided to them. This provided energy enables them to rebound back to their combined state when they are exposed to external environment like moisture, oxygen etc. For example: when iron is exposed to external conditions, it undergoes corrosion and produces brown colored hydrated ferrous oxide. This shows that corrosion is a process which is contrary to metal extraction.

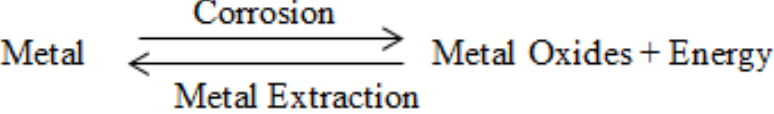

Sometimes, corrosion also takes place in essentially clean and unpolluted waters at a temperature of about $130^{\circ} \mathrm{C}$ on the product side. Such type of corrosion is classical hot spot corrosion (Charng \& Lansing, 1982).

\section{FACTORS AFFECTING CORROSION}

The rate of corrosion mainly depends on two factors:

1) Nature of metal

2) Nature of corroding environment.

Some other factors that affect corrosion are purity of metal, nature of surface film, nature of corrosive product, temperature, humidity of air and $\mathrm{pH}$ of electrolyte.

\subsection{Nature of metal:}

It further depends upon:
(a) Position in galvanic series
(b) Purity of metal
(c) Nature of surface film
(d) Nature of corrosive product.

(a) Position in galvanic series: When we have two metals of different types and are connected electrically in a given electrolyte, the metal with higher oxidation potential or the metal which is present at a higher level in galvanic series is corroded whereas the rest is protected. Further, the rate of corrosion also depends upon the difference of the positions of the two metals.
Rate of corrosion is directly proportional to the difference of the position of the two metals i.e. more the difference, faster is the rate of corrosion. The corrosion susceptibility of metals is shown in Fig. 1.

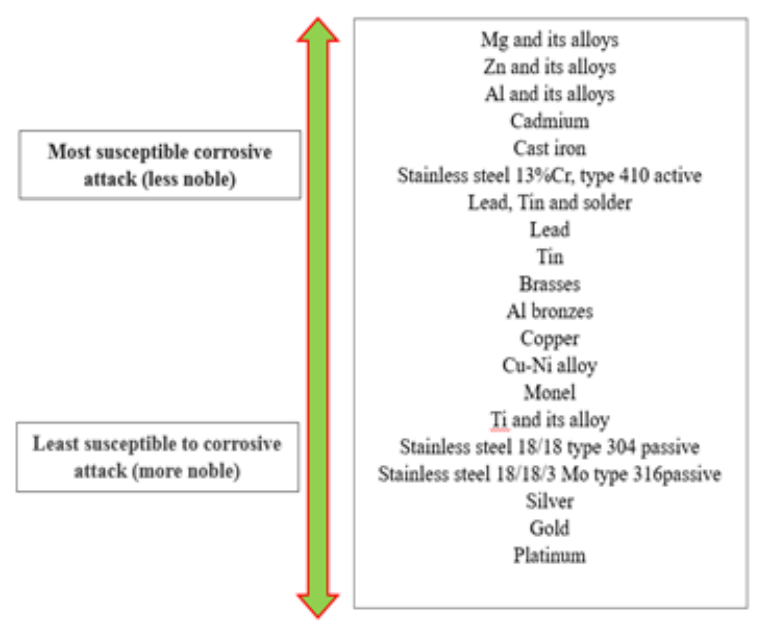

Figure 1. Corrosion susceptibility of metals

For example, if we have cast iron and copper as the two different metals in a given electrolyte, then cast-iron is corroded and copper is protected.

(b) Purity of metal: Generally, the rate of corrosion increase with increase in addition of impurities. This is so because; impurities form tiny electrochemical cells where the anodic part gets corroded. For example: $\mathrm{Zn}$ containing impurities like $\mathrm{Fe}$ or $\mathrm{Pb}$ corrodes faster.

(c) Nature of surface film: All the metals get covered with a thin surface film of the metal oxide in an aerated atmosphere. The ratio of volumes of metal oxide to the metal determines the effect of surface film. It is known as "specific volume ratio". Greater the ratio, lesser is the oxidation rate. For example: The specific volume ratio of $\mathrm{Ni}, \mathrm{Co}$ and $\mathrm{W}$ are $1.6,2.0$, and 3.6 respectively. The rate of oxidation of $\mathrm{W}$ is least even at the elevated temperature.

(d)Nature of corrosive product: The corrosion comparatively proceeds at a faster rate if the product formed, is soluble in the corrosive medium. Also if the corrosive product is volatile, it evaporates as soon as it is formed, thereby metal surface is exposed for further attack. In this way, corrosion further exceeds.

\subsection{Nature of corroding environment}

It further depends on:

(a) Temperature

(b) Humidity of air

(c) Effect of $\mathrm{p}^{\mathrm{H}}$

(a)Temperature: The rate of corrosion increases with the rise in temperature. The rate of corrosion is expected to be almost double for every $10^{0}$ rise in temperature, provided other biological conditions are kept constant 
(Levy, 1995). This increase is usually represented by an exponential curve. However, one encounters not only the simple dependence upon temperature given by exponential curves. In number of cases, the change of temperature modifies the influence of other factors also. The increase of temperature acts in two different ways (Décarie \& Geider, 2017).

(b) Humidity of air: It also plays a great role in deciding the rate of corrosion. The rate of corrosion increases sharply above a special point of relative humidity. This is called critical humidity. The reasons for this increase of corrosion with humidity are that the oxide film has the tendency to absorb moisture thus creating another electrochemical corrosion. Also, the moisture present in the atmosphere will furnish water to the electrolyte which is essential for setting up of an electrochemical cell.

(c) Effect of $p^{H}$ : It is the most important factor to determine the rate of corrosion. Generally, lower is the $\mathrm{p}^{\mathrm{H}}$, greater is the corrosion. This shows that acidic media having $\mathrm{p}^{\mathrm{H}}$ less than 7 are more corrosive than alkaline or neutral media [9]. The first and the simplest diagram of corrosion vs. $\mathrm{pH}$ of the solution is the diagram for the noble metals (gold and platinum) is shown in Fig. 2. The dependence of the rate of corrosion on $\mathrm{pH}$ of solution is given by a straight line near the bottom of the diagram. In other words, the diagram shows that the rate of corrosion is extremely low and actually depends very little on $\mathrm{pH}$ of the solution. For the very high values of $\mathrm{pH}$, one can observe a slight rise of the curve. In other words, there is some perceptible increase in corrosion. However, this rise has very little practical significance (Décarie \& Geider, 2017).

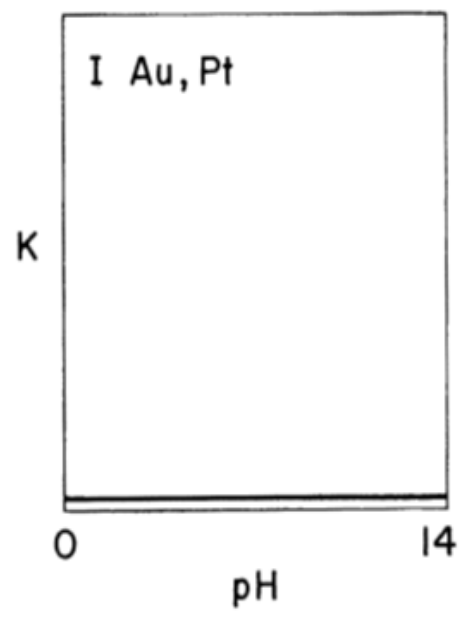

Figure 2. Corrosion vs. pH for the noble metals (gold and platinum)

The second type of $\mathrm{pH}$ corrosion diagram belongs to some technically important metals as zinc, aluminum and lead (Fig. 3). As the diagram shows, there is for these metals a sharp increase of the corrosion rate, both in acidic and alkaline mediums as compared to the neutral solutions. This shape of the curve becomes plausible when one takes into consideration that the oxides of above mentioned metals are soluble both in acid and in alkaline solutions (Décarie \& Geider, 2017).

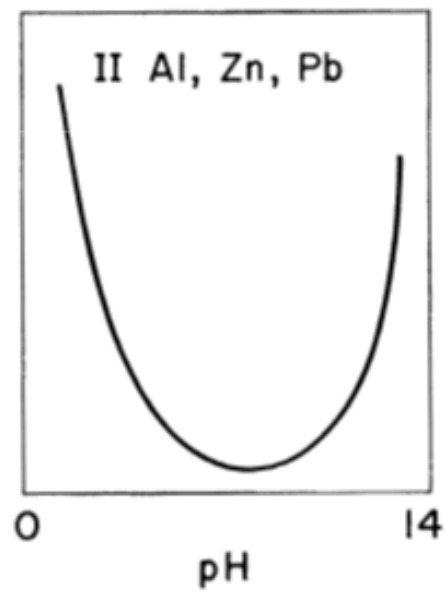

Figure 3. Corrosion vs. $\mathrm{pH}$ for the metals (zinc, aluminum and lead)

\section{CORROSION COST TO SOCIETY}

Corrosion as being one of the most serious problems in our society is resulting into losses each year in hundreds of billions of dollars (Berradja, 2019). Some major losses due to corrosion are enlisted below:

(i) It damages industrial machines and unpredictable machinery failure, which could lead to loss of life.

(ii) It damages metallic equipment such as boiler tubes in thermal power plants (Kumar et al., 2018; Kumar et al., 2018; Shi et al., 2003; Kumar et al., 2020; Sharma et al., 2019; Kumar et al., 2019).

(iii) It reduces the overall value of that product and wastes the valuable resources.

(iv) Some metallic properties such as conductivity, ductility, malleability, luster etc. are lost due to corrosion.

(v) About $20 \%$ of the total production of iron is wasted annually every year due to corrosion.

(vi) It also contaminates portable water.

Hence, to minimize the effects of corrosion, we must carefully observe its mechanism.

\section{ROLE OF OXYGEN IN CORROSION}

Atmospheric oxygen reacts with metals to form their respective oxides. Some metals like $\mathrm{Li}, \mathrm{Na}, \mathrm{Ka}$, etc. are oxidized at low temperature whereas other like Ag, Au, $\mathrm{Pt}$, etc. are oxidized at higher temperature. When the metal surface is exposed to atmosphere, the metal surface gives electrons whereas oxygen accepts electrons. The metal changes into metal ions whereas the oxygen changes into oxide ions. 


$$
\begin{gathered}
2 \mathrm{~A} \longrightarrow 2 \mathrm{~A}^{\mathrm{n}+}+2 \mathrm{ne}^{-} \\
\text {Overall: } 2 \mathrm{~A}+\mathrm{nO}_{2} \longrightarrow 2 \mathrm{nO}^{2-} \\
\longrightarrow 2 \mathrm{~A}^{\mathrm{n}+}+2 \mathrm{nO}^{2-} \longrightarrow \mathrm{A}_{2} \mathrm{O}_{\mathrm{n}}
\end{gathered}
$$

Where, A is any metal.

The oxide layer prevents further oxidation. The oxide layer formed may be porous or non-porous. The porous layer can undergo further oxidation through the pores and cracks and it continues till the entire metal surface is oxidized whereas non porous layer acts as a protective layer and prevents further oxidation. To check whether the layer formed is porous or nonporous, we have "Pilling-Bedworth" Rule. "PillingBedworth" Rule: According to this rule, an oxide film is protective (non-porous) if the volume of the oxide is at least equal to or greater than the volume of the metal from which it is formed. However, if the volume of the oxide is less than the volume of the metal, the oxide film is non-protective (porous). For example: metals like $\mathrm{Al}$, form oxide layer having greater volume than the metal so sit form non porous oxide layer and further oxidation of the metal is prevented. On the other hand, Fe form oxide layer having lesser volume as compared to the metal so it forms porous oxide layer which allows further attack to atmospheric oxygen through the pores till the metal surface is completely corroded. The limiting rate of corrosion varies directly with oxygen when oxidizing agent is dissolved oxygen (Obrecht \& Pourbaix, 1967).

\section{CORROSION MECHANISM}

Corrosion involves exchange of electrons from anode to cathode in a given conductive solution. The metal at anode undergoes liberation of free electrons (oxidation) whereas the cathodic metal accepts the electrons (reduction). The metal which has the higher reduction potential acts as anode whereas the other at lower potential acts as cathode, so the anodic metal gets corroded. For corrosion, these conditions must be fulfilled:

1. There must exist separate regions (cathodic and anodic) between which current might flow through conducting medium.

2. At anode, oxidation of metal occurs due to which the metal surface is depleted due to combination with oxygen. Hence, corrosion always takes place at anode.

$$
\mathrm{A} \longrightarrow \mathrm{A}^{\mathrm{n}+}+\mathrm{ne}^{-} \quad \text { (oxidation) }
$$

3. At cathode, reduction takes place in which dissolved oxygen accepts the electrons from the anode and form ions such as $\mathrm{OH}^{-}$or $\mathrm{O}^{2-}$

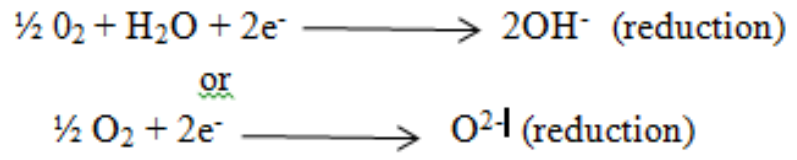

4. Due to combination of ions liberated at different electrodes, a corrosive product is formed somewhere in between these electrodes.

5.

\subsection{Anodic Reactions}

Corrosion takes place at anode. At anode, oxidation or loss of electron of metal takes place. Usually, the metal with higher reduction potential is taken as anode. The anodic metal gets transformed into its respective ion with the loss of electron(s).

$$
\mathrm{A} \longrightarrow \mathrm{A}^{\mathrm{n}+}+\mathrm{ne}^{-}
$$

\subsection{Cathodic Reactions}

At cathode, reduction takes place i.e. metal accepts the electrons from the anode. This can happen in two ways: by evolution of hydrogen and by absorption of oxygen.

\subsubsection{By evolution of hydrogen}

It is the corrosion process in which hydrogen is liberated. This generally takes place in acidic medium or alkaline medium where $\mathrm{H}^{+}$ions accept the anodic electrons to give $\mathrm{H}^{2}$.

$$
2 \mathrm{H}^{+}+2 \mathrm{e}^{-} \longrightarrow \mathrm{H}_{2}(\text { gas) }
$$

For example Fe metal

Reaction at Anode:

$\mathrm{Fe} \longrightarrow \mathrm{Fe}^{2+}+2 \mathrm{e}^{-}$

Reaction at Cathode:

$$
2 \mathrm{H}_{3} \mathrm{O}^{+}+2 \mathrm{e}^{-} \longrightarrow \mathrm{H}_{2} \text { (gas) }
$$

Overall Cell Reaction:

$$
\mathrm{Fe}+2 \mathrm{H}_{3} \mathrm{O}^{+} \longrightarrow \mathrm{Fe}^{2+}+\mathrm{H}_{2} \text { (gas) }
$$

\subsubsection{By absorption of oxygen}

It is the corrosion process in which oxygen is absorbed. This generally takes place in neutral medium (usually $\mathrm{NaCl}$ is used as a conducting medium) in which $\mathrm{O}_{2}$ is absorbed to give $\mathrm{OH}^{-}$ions. 


$$
1 / 2 \mathrm{O}_{2}+\mathrm{H}_{2} \mathrm{O}+2 \mathrm{e}^{-} \longrightarrow 2 \mathrm{OH}^{-}
$$

For example Fe,

Reaction at Anode:

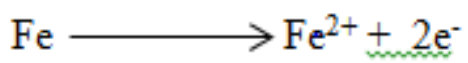

Reaction at Cathode:

$$
1 / 2 \mathrm{O}_{2}+\mathrm{H}_{2} \mathrm{O}+2 \mathrm{e}^{-} \longrightarrow 2 \mathrm{OH}^{-}
$$

\section{Overall Cell Reaction:}

The $\mathrm{Fe}^{2+}$ ions formed at anode and $2 \mathrm{OH}^{-}$ions formed at cathode come to form ferrous hydroxide $\mathrm{Fe}(\mathrm{OH})_{2}$.

$$
\mathrm{Fe}^{2+}+2 \mathrm{OH}^{-} \longrightarrow \quad \mathrm{Fe}(\mathrm{OH})_{2}(\mathrm{ppt})
$$

\section{TYPES OF CORROSION}

The various types of corrosion are classified into following categories as shown in Fig. 4.

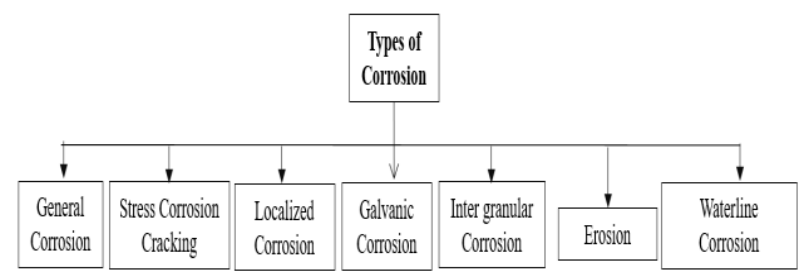

Figure 4. Types of Corrosion

\subsection{General Corrosion:}

It is also known uniform corrosion or dry corrosion; it is the type of corrosion which perishes the barren metal surface more or less, uniformly. It can also be defined as a type of corrosion which proceeds at same rate over the entire barren area. Oxygen acts as a foremost cause of this corrosion. The most common materials which show general corrosion are cast iron and steel. When they are exposed to moist atmosphere, they give rust-like appearance.

$$
\begin{gathered}
2 \mathrm{~A} \longrightarrow 2 \mathrm{~A}^{\mathrm{n+}}+2 \mathrm{ne}^{-} \\
\text {Overall: } \stackrel{\mathrm{n} 02+2 \mathrm{ne} \cdot}{\longrightarrow} 2 \mathrm{n} \mathrm{n}^{2 \cdot} \\
\end{gathered}
$$

Where, A is any metal.

Experiments on the behavior of dry metals show that no corrosion occurs when they are kept over sulfuric acid and only show superficial corrosion when they are kept over water (Makhlouf et al. 2019).

\subsection{Stress Corrosion Cracking}

Stress corrosion cracking is a phenomenon that is of interest to a wide range of metal users. When it occurs under service conditions, often without any prior indication of impeding collapse, its effect may be catastrophic (Martinchek \& Max, 2000). The schematic diagram is shown in Fig. 5.

It is the type of corrosion which results from the stress applied on the material (present initially in inert environment) and thus results in emergence of crack in corrosive environment. It can be accelerated by either residual internal stresses in the metal or externally applied stress (Eliaz, 2019). It mostly occurs at high temperatures. It is more common in alloys than in metals. SCC can only occur if the following three factors are fulfilled: (i). Presence of susceptible material (ii) subjection to corrosive environment and (iii) tensile stresses.

The problem cannot be said to be a diminishing one, since the number of alloys known to be susceptible to stress corrosion cracking and the number of environments that cause cracking have both risen till now. Over the last 25 years or so a large, widely dispersed and mainly un-coordinated effort has been made in the Western World to cope with stress corrosion cracking (Martinchek \& Max, 2000). An additional factor of all cracking processes that must be included in determining the mechanisms of stress corrosion cracking is the role of time. A quantitative determination of a stress corrosion mechanism must include not only what is happening either in metallurgical or electrochemical terms but, perhaps more importantly, it must indicate the rates at which such occurrence is operating. It has been suggested in very general terms that the important feature in a stress corrosion crack propagation process is the time in which a sequence of events occurs, e.g. the rate of slip step emergence or the rate of re-passivation (Martinchek \& Max, 2000).

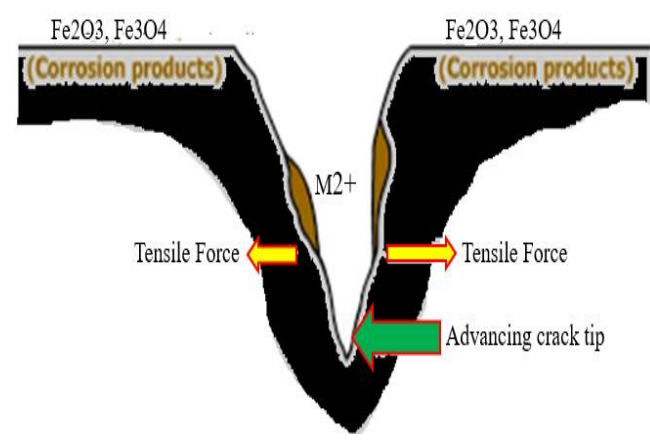

Figure 5. Schematic diagram of stress corrosion cracking 


\subsection{Localized Corrosion}

Localized corrosion is quite different from general corrosion. General corrosion takes place at a relatively larger area whereas localized corrosion takes place comparatively at a smaller area (Michael \& Pudji, 1996). This corrosion occurs when the small areas of a metal surface are corroded much easily as compared to the whole in a corrosive environment. These small areas are partially corroded from the metal surface due to the presence of corroding medium at a faster rate. The area with limited supply of oxygen becomes anode whereas the other with full supply becomes cathode. It is further of two types: (i) Pitting corrosion (ii) Crevice corrosion

\subsection{Pitting Corrosion}

Pitting corrosion is an important type of localized corrosion. This type of corrosion initially occurs in a comparatively small area on a material. After sometime, the area gets larger and deeper, which forms pits in the surface. In this type of localized corrosion, pits (or holes) are established on the surface of material. An area covered by impurity or water has lower concentration of oxygen so it acts as anode while the other acts as cathode. It is supposed that electrochemical mechanism is responsible for the dissolution of the metal (Hoar \& Agar, 1947). Till now, two theories are widely used: One is suggested by Hoar. He linked the emergence and growth of the pits with the effect of increase of acidity level of the solutions at active sections (Hoar, 1949; Vaniukova \& Kabanov, 1948). Another is suggested by Russian investigators. They linked the formation of pits with the displacement from the metal surface by anions (Kabanov et al, 1947; Altenpohl \& Zeiger, 1965; Kolotyrkin, 1963; CurleyFiorino \& Schmid, 1980; Akpanyung \& Loto, 2019; Popova \& Kabanov, 1961; Kolotyrkin, 1963). The ratio of deepest pit to the average penetration is known as pitting factor. Pitting factor can be used to check the intensity of pitting corrosion. It is much harmful type of corrosion as it is strenuous to detect, foretell and design against. It is usually observed in passive materials. The presence of non-uniformities adds fuel to the rise of this corrosion. The reaction may proceed as:

$$
\begin{aligned}
& \text { At Anode: } \quad \mathrm{Fe} \longrightarrow \mathrm{Fe}^{2+}+2 \mathrm{e}^{-} \\
& \text {At Cathode: } \quad 1 / 2 \mathrm{O}_{2}+\mathrm{H}_{2} \mathrm{O}+2 \mathrm{e}^{-} \longrightarrow 2 \mathrm{OH}^{-} \\
& \text {Overall: } \quad \mathrm{Fe}^{2+}+2 \mathrm{OH}^{-} \longrightarrow \mathrm{Fe}(\mathrm{OH})_{2} \text { (ppt) } \\
& \mathrm{Fe}(\mathrm{OH})_{2}(\text { ppt }) \longrightarrow \mathrm{Fe}(\mathrm{OH})_{3}
\end{aligned}
$$

\subsection{Crevice Corrosion}

Crevice corrosion is one of the major practical problems especially in marine applications (North \& Macleod, 1987; Tan et al. 2001). It mainly affects Stainless Steels. Presence of chloride adds more difficulties while handling with crevice corrosion (Prawoto \& Ibrahim,
2009; Davis et al., 2001; Tan et al., 2011). It is a restricted space corrosion to which the approach of working fluid from the corrosive environment to the space (crevices) is inadequate. The joint area has comparatively lower content of oxygen as compared to the outer area, so joint area acts as anode whereas the outer area acts as cathode. This corrosion is started by concentration gradients. The grouping up of chlorides ions inside a crevice will begin it. It occurs at comparatively lower temperature than pitting corrosion. Various factors that impact crevice corrosion are as follow.

(i). The type of material i.e. alloy, metal

(ii).Geometric characteristics of crevices such as surface roughness

(ii).Environmental conditions such as $\mathrm{pH}$ level, temperature, etc.

\subsection{Inter Granular Corrosion}

It is also called Inter granular attack (IGA), this corrosion occurs when the margins of the metal surface are more prone to corrosive environment than at the core. This corrosion helps to veil the material's corrosion resistance under many circumstances. This is known as IGA Test. The Inter granular corrosion of aged $\mathrm{Al}-4 \% \mathrm{Cu}$ alloys has been the subject of numerous investigations. It is generally agreed that the microstructure of the aged Al-Cu alloy is the one represented below in the Fig.6 (Kolotyrkin, 2013). Inter-granular Corrosion is not affected with the addition of impurities like $\mathrm{C}, \mathrm{N}, \mathrm{O}, \mathrm{Mn}$ and $\mathrm{S}$ whereas addition of $\mathrm{Si}$ and $\mathrm{P}$ affects the corrosion (Zhang \& Farnkel, 2007).

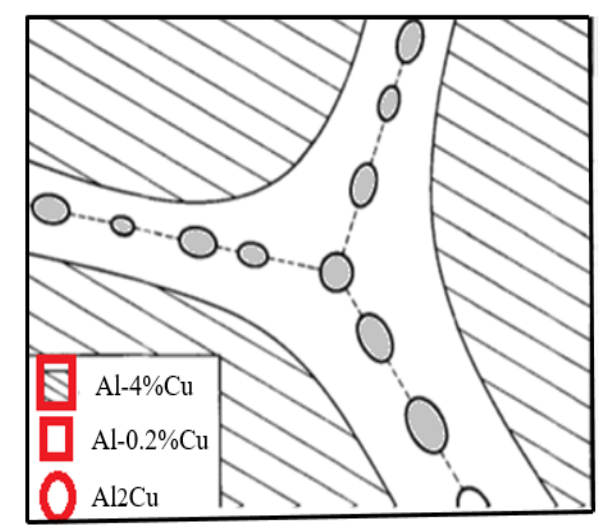

Figure 6. Schematic representation of the microstructure of an aged $\mathrm{Al}-4 \% \mathrm{Cu}$ alloy.

\subsection{Galvanic Corrosion}

According to electrochemistry, the galvanic corrosion reaction is caused at discrete portions on the metallic surface by an anodic portion and a cathodic portion (Kadhim \& Albdiry, 2017). The preferential corrosion of one metal (in presence of a suitable electrolyte) over the other, when both are having an electrical contact is known as galvanic corrosion. It is also known as 
bimetallic corrosion. It is an electrochemical phenomenon of two unlike metals electrically connected and placed in a suitable electrolyte. The metal at cathode is protected while the metal at anode is corroded. Only unlike metals show galvanic corrosion. The less reactive metal is assigned as cathode while the other is assigned as anode. The rate of galvanic corrosion is directly proportional to the potential difference between the two metals. It increases with the increase in potential difference between the two metals. The reaction of galvanic corrosion is represented in Fig.7. This potential difference is calculated by using the relation: P.d. $=-\mathrm{dG} / \mathrm{nF}$

Where; $\mathrm{dG}$ is the Gibbs free energy of the reaction, $\mathrm{n}$ is the number of moles of electrons transferred and $\mathrm{F}$ is the Faraday constant whose value is $23.06 \mathrm{kcal} / \mathrm{volt}$.

Let us have an example in which $\mathrm{Zn}$ and $\mathrm{Cu}$ are electrically connected. Since, in electrochemical series, $\mathrm{Zn}$ lies at a higher position than $\mathrm{Cu}$, so $\mathrm{Zn}$ acts as anode whereas $\mathrm{Cu}$ acts as cathode. This means that $\mathrm{Zn}$ undergoes loss of electrons whereas $\mathrm{Cu}$ accepts electrons. Due to lesser noble nature of $\mathrm{Zn}$ as compared to $\mathrm{Cu}, \mathrm{Zn}$ undergoes corrosion. In Acidic solution,

$$
\mathrm{Zn}+2 \mathrm{H}^{+} \longrightarrow \mathrm{Zn}^{2+}+\mathrm{H}_{2}
$$

In neutral or slightly alkaline solution,
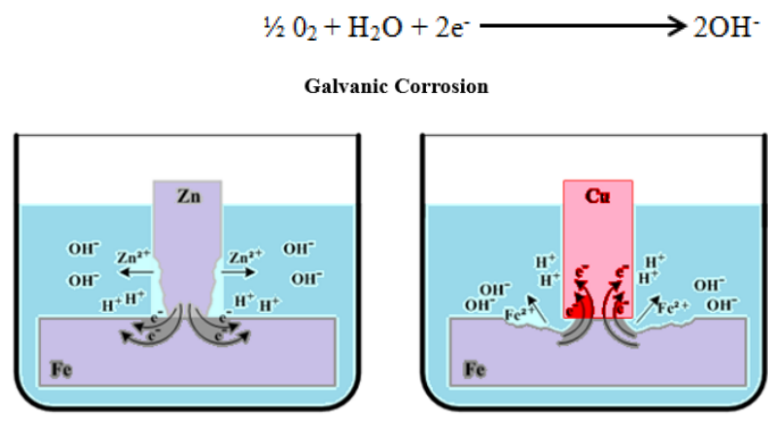

Figure 7. Schematic diagram of Galvanic Corrosion

\subsection{Erosion}

Due to the relative movement between the metal surface and corrosive fluid, the metal surface gets corroded. This is known as erosion. When the fluid contains solid particles that are harder than the affected metal surface, erosion will occur by the combined action of corrosion and abrasion whereas when the fluid contains the particles which are softer than the metal, erosion will occur by corrosion and attrition (Kumar et al. 2018). The rate of relative flow gives the idea about abrasion. The mechanism of chipping and cracking determines the cause of erosion, which occurs due to concurrent formation and removal of scale from the surface of material (Prutton \& Frey, 2016).

The cavitation corrosion is the special form of erosion. The vapor bubbles in liquids near the metal surface form and collapse, thus giving rise to this corrosion. Some general techniques to restrict erosion are: Use harder materials (ii) Use lower velocity of the liquid.

\subsection{Waterline Corrosion}

This type of corrosion occurs in the metallic tanks. When the tanks are partially filled with water, the area below the surface of water is poorly oxygenated and thus acts as anode whereas the area above the line of water has significant amount of oxygen and thus acts as cathode. The water line corrosion setup is represented in Fig.8. Thus the area just below the level of water is corroded and the area above the level is protected.

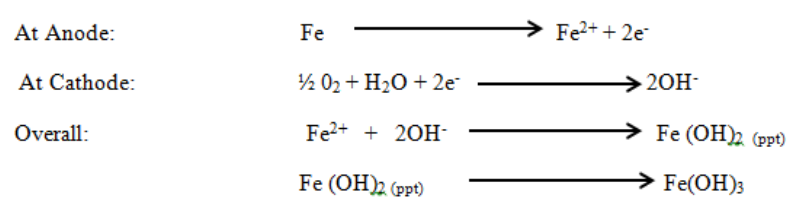

Water line corrosion

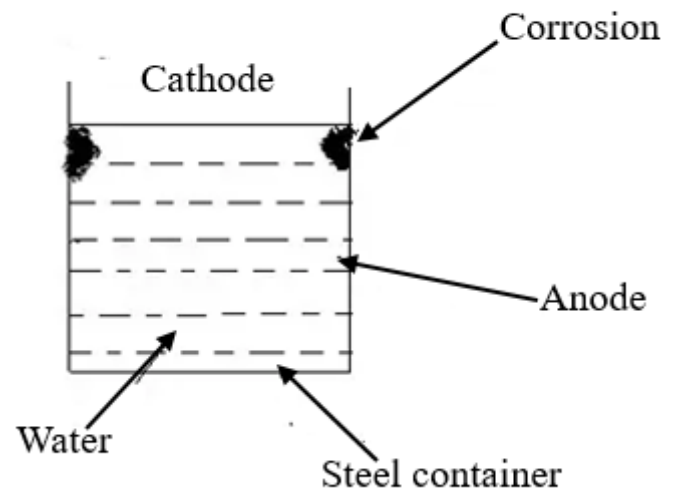

Figure 8. Diagram of water line corrosion setup

Mostly, marine engineers face this type of corrosion. It can be reduced by using anti fouling paints to some extent.

\section{CORROSION PREVENTION}

Generally, noble metals don't corrode, but because of their high cost, they cannot be used for common purposes (Kumar et al. 2018). So, in order to protect many kinds of machinery from corrosion, we have to use other metals and alloys to fabricate them as depicted in Fig.9. 


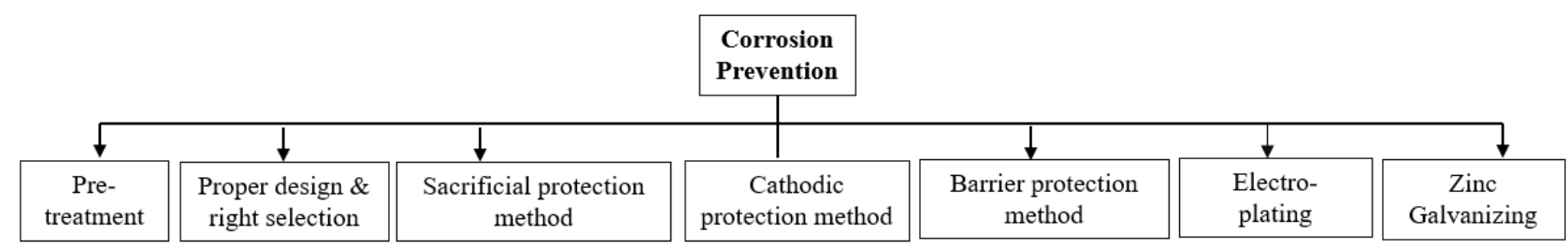

Figure 9. Corrosion prevention methods

\subsection{Pre-treatment of Metals}

Before the adaptation of any protective measures, the surface of the metal should be properly cleaned. Degreasing is one of the most widely adopted methods for the pre-treatment. A volatile organic solvent like trichloroethylene helps to dissolve the oily as well as greasy surface films (Jones \& Foreman, 2015). Acid pickling can also be taken as another method of removing scale than mechanical cleaning. Before any coating can be applied, it is necessary to properly prepare the metal surface. Oils and grease can also be removed from the surface by washing with alkali solution (Jones \& Foreman, 2015). Another method of cleaning is applying flame from a kerosene burner. The old paint, oil and grease are removed because of sudden expansion of metals. Now after some pre-treatments, we can use now various methods to resist corrosion. Some of them are explained below.

\subsection{Proper Design and Selection of Right Material}

The design of the material should be such that corrosion should be minimum. Its important principles are:

(a) Proper Design: In the presence of a corroding environment, avoid the contact of two dis-similar metals.

(ii) In case it is necessary to make a contact of two different metals, the metal to be made anode must have as large area as possible whereas the other metal must have at least area as possible.

(iii) If two dissimilar metals in contact have to be used, they should be as close to each other as possible in the electrochemical series.

(iv) Whenever, the direct contact of dissimilar is unavoidable, an insulating material may be applied in between them to avoid direct metal-metal electrical contact.

(v) Sharp corners must be avoided as they favor the gathering up of solids.

(vi) The metal should never be painted or coated because any break in coating would result in rapid localized corrosion.

(b) Selecting the Right Material: The properties for the construction of right materials are:
Tensile strength, highly resistant to corrosion and cheap The selection of the material is carried out by following steps:

a. Prior selection : This type of selection is made on the basis of past experience and safety aspects.

b. Testing in lab: In this, the suitable material is reevaluated under the given conditions

c. Explanation of laboratory results: In this, the results like effect of impurities, excess temperature, pressure, etc. (Shibli \& Meena, 2015).

\subsection{Sacrificial Method}

Sacrificial protection means protecting the metal by covering its surface with a layer of another metal which is more active or more electropositive than it (Popov et al. 2015). The metal surface which is more active loses electrons in preference to the other and converts itself into an ionic state by losing electrons. As the time passes, the more active metal gets fully used up but only till it is present there. As an example, $\mathrm{Zn}$ is usually coated over Fe to prevent it from rusting. This process is called Galvanization. $\mathrm{Zn}$ being more electropositive than $\mathrm{Fe}$ acts as anode and gets corroded whereas $\mathrm{Fe}$ is protected till the $\mathrm{Zn}$ is present.

The $\mathrm{Zn}$ forms an invisible protective layer of basic zinc carbonate $\left[\mathrm{ZnCO}_{3} \cdot \mathrm{Zn}(\mathrm{OH})_{2}\right]$ over the surface of iron when it comes in contact with moisture, $\mathrm{CO} 2$ and oxygen. No doubt that Fe loses its luster but this layer also protects it from further corrosion.

Fe can also be coated with $\mathrm{Cu}$ by a solution of copper sulphate but it is not much useful as the corrosion of Fe is increased in case of any scratch or crack on the coating. That's why; $\mathrm{Zn}$ is most often used over any other material for electroplating over Fe.

\subsection{Cathodic Protection}

This is a widely used method for the prevention of corrosion. It is mostly used to prevent the pipes from rusting. It is performed by providing an electric current to the pipes (which is to be protected) from outside source.

The iron object, which has to be protected, is connected with a more active metal. The iron object becomes cathode whereas the metal used for protecting becomes anode. Due to oxidation, the anode is slowly used up to 
its ions due to loss of electrons. The iron metal is protected from rusting only till the protective metal is present and only till the electrode potential is maintained below -0.62 V (Kumar et al. 2019). Metals often used for rusting are $\mathrm{Mg}, \mathrm{Zn}$ and $\mathrm{Al}$ which are also known as sacrificial anodes. It is usually of two types:

(a). Sacrificial anode method: In this method, the anode corroded sacrificially to protect the material. That's why, it is known as sacrificial anode method. Usually zinc or magnesium is used for making galvanic anodes because they have higher oxidation potential than the steel. The schematic diagram of internal and external protection of water pipe using sacrificial anodic methods is shown in Fig. $10(a, b)$.

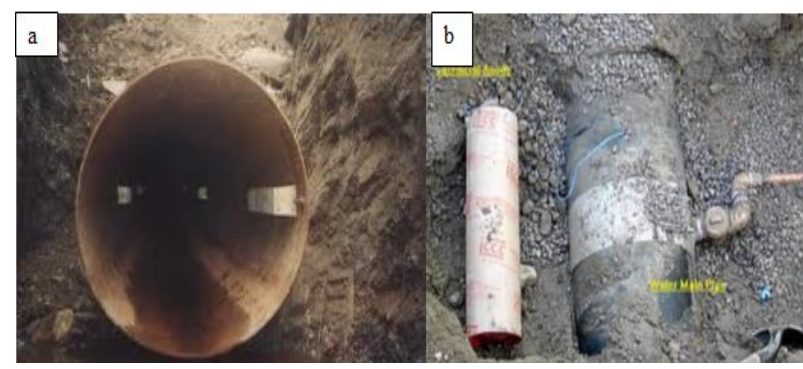

Figure 10. (a) Internal protection of water pipe-line using sacrificial anodic method (b) External protection of water pipe-line using sacrificial anodic method

(b) Impressed current method: In Impressed current method, both the anode and the material (which is to be protected) are joined by an insulated wire internally and so the path of current is from the anode, through the electrolyte, to the material.

It is much similar to the galvanic system. The only difference is that the galvanic system depends on the difference in oxidation potential between the anode and the material whereas in impressed current method, the external supply is provided for the current to flow.

\subsection{Barrier Protection}

The metal surface may be coated for protection against corrosion. Most of these coatings perform as a barrier between the metallic surface and corrosive environment and therefore, this method is called barrier protection (Qian \& Fang, 2015). This is one of the simplest methods to prevent corrosion. In this method, a suitable barrier is placed between the metal surface and atmosphere. Thus, the metal surface remains protected by the action of air, water and carbon dioxide and does not corrode. The barrier protection can be attained by using any of the following methods:

a. By coating paints, oils or grease over the metal surface

b. By coating the metal surface with non-corroding metals

c. By coating the metal surface with certain chemicals
Graphene is widely used in barrier protection method because of its inert nature, unique structure and electrical properties (Armijo, 1968). Graphene contains carbon atoms that are strongly bonded to form a hexagonal like structure. It acts as inert under that condition also where other would undergo chemical reactions (Armijo, 1968).

\subsection{Electroplating}

The Italian chemist Luigi Brugnatelli invented electroplating in 1805. After multiple attempts and failures, he successfully plated a thin layer of gold onto silver (Giurlani \& Innocenti, 2018). It is the method of coating one metal over another by passing electrical current through a solution (Fig.11). It is used for multiple purposes such as decorative purposes, appearance and protection. Chromium plating can be used to coat over the vehicle wheel rims, gas burners to resist corrosion. Nickel plating is used for decorative purposes and also for various machinery parts. For electroplating following procedure is used.

The foremost step is to prepare a clean work piece. This is done by dipping the work piece in various solutions such as alkaline cleaners, degreasers, etc. This helps in removal of dirt, grease and contaminants from the piece. After having a pure work piece, it is connected to the negative terminal (cathode) of the dc power supply. The metal, which is to be plated over the work piece, is connected to the positive terminal (anode) of the dc power supply.

An ammeter is connected in series and a voltmeter is connected in parallel to the cell in order to measure the current and voltage of the cell.

The work piece is then polished thoroughly.

The Faraday's Law is helpful in determining the thickness of the coating. The coating quality depends on uniformity of thickness and continuity.

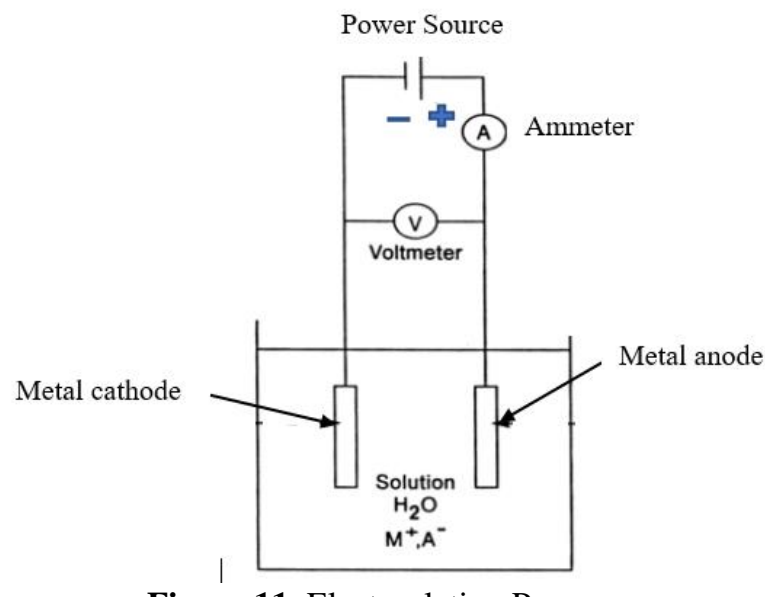

Figure 11. Electroplating Process 


\subsection{Zinc Galvanizing by Hot Dipping Method}

It is a process in which the cleaned steel is dipped in molted zinc. Temperature is maintained at near about $445-450^{\circ} \mathrm{C}$, that's why it is known as hot dipping method (Fig. 12). As compared to electro-plating, hot dipping method is much better and is most often used. This is so because the coating of hot dipping method provides greater corrosion protection to the metal as compared to the electroplating (Sahoo \& Davim, 2017). This method provides a variety of properties such as low cost, less weight, can be easily recycled and great strength.
The two folded protection nature of the coating is the reason for the boundless use of hot dip galvanization. This coating is formed when a ferrite substrate is immersed into molten zinc, so this coating is a mixture of different stages, which are formed due to reactions between iron and zinc (Lynch, 2001; Goldstein, 1960). During hot dip galvanization, the steel is immersed in a container which must contain a minimum of $98 \%$ pure molten zinc (Evgueni et al, 2004). The zinc metal then reacts with the iron on the steel surface to form a zinc/iron intermetallic alloy. The excessive zinc is removed by the process of centrifuging.

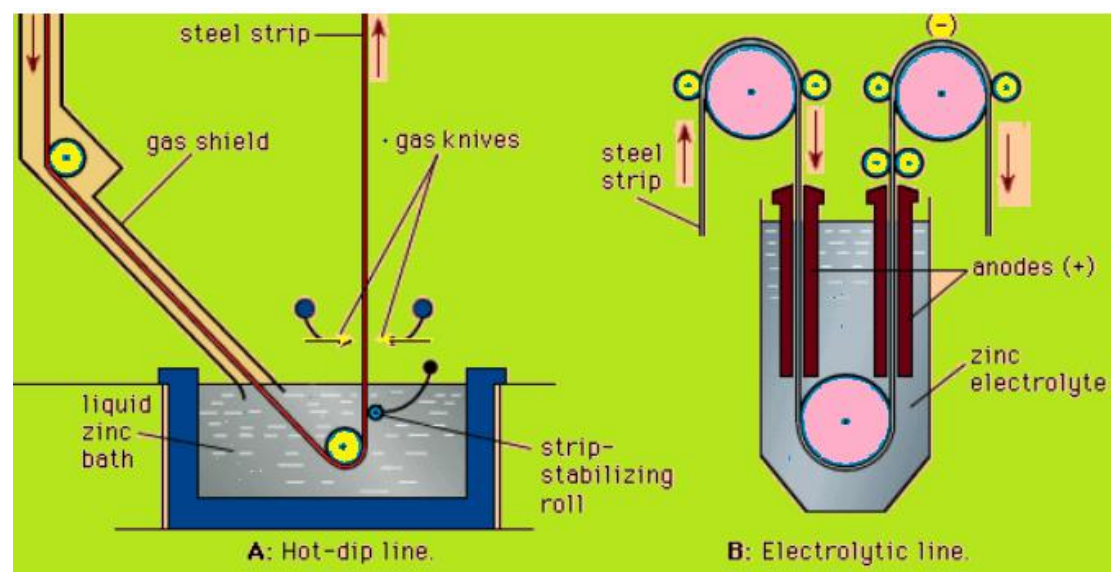

Figure 12. Galvanization of steel by hot dipping and electroplating

\section{CONCLUSION}

Corrosion is the natural phenomena that cause degradation and failure of component. Although, the general or uniform attack leads to maximum destruction of metal component, but it is easier to prevent.
However, other types of corrosion such as inter granular or stress corrosion are very destructive for engineering components. All these types of corrosion have impact on environment, economy and human life. It has been concluded from the results of various researches that timely protective measures could resist corrosion.

\section{References:}

Akpanyung K. V., \& Loto, R. T. (2019). Pitting corrosion evaluation: a review. J. Phys.: Conf. Ser. 1378 022088, 1-15.

Altenpohl, D., \& Zeiger, H. (1965). Corrosion. in: aluminum. Springer. 19. https://doi.org/10.1007/978-3-662-302453_17

Armijo, J. S. (1968). Intergranular corrosion of nonsensitized austenitic stainless steels. Corrosion, 24(1), 24-30. https://doi.org/10.5006/0010-9312-24.1.24

Berradja, A. (2019). Electrochemical Techniques for Corrosion and Tribocorrosion Monitoring: Fundamentals of Electrolytic Corrosion. Corrosion Inhibitors. doi:10.5772/intechopen.85392.

Charng, T., \& Lansing, F. (1982). Review of corrosion causes and corrosion control in a technical facility. Jet Propulsion Lab., Pasadena, CA (USA).

Curley-Fiorino, M. E. \& Schmid, G.M. (1980). The effect of the Cl- ion on the passive film on anodically polarized 304 stainless steel. Corrosion Science, 20(3), 313-329. https://doi.org/10.1016/0010-938X(80)90002-5

Davis, J. R. (2001). Surface engineering for corrosion and wear resistance. ASM International, 279.

Décarie, E. L., \& Geider, R. J. (2017). Predictions of response to temperature are contingent on model choice and data quality. Ecol Evol, 7(23), 10467-10481.

Eliaz, N. (2019). Corrosion of Metallic Biomaterials: A Review. Materials. 12(3),400-407. doi: 10.3390/ma12030407

Evgueni, B., Nikolay P., \& Boris S. (2004). Truncated-determinant diagrammatic monte carlo for fermions with contact interaction. Phys. Rev. 70, 15-28. 
Fernandes, J. S., \& Montenor, F. (2015). Corrosion. Materials For Construction And Civil Engineering, 2, $679-716$. doi:10.1007/978-3-319-08236-3_15

Giurlani \& Innocenti, M. (2018). Electroplating for decorative applications: recent trends in research and development walter. Coatings, 8, 149-260. doi:10.3390/coatings8080260

Goldstein, E. M. (1960). The Corrosion and oxidation of metals: scientific principles and practical applications. $J$. Chem. Educ. 37, 662-672.

Hoar, T. P. (1949). Bulk metallic glasses: an overview. Trans. Faraday Soc. 45, 683-692.

Hoar, T. P. \& Agar, J. N. (1947). Factors in throwing power illustrated by potential-current diagrams. Discuss. Faraday Soc. 6-28.

Jones, F. R. \& Foreman, J. P. (2015). The response of aerospace composites to temperature and humidity in Polymer Composites in the Aerospace Industry. Woodhead Publishing, 335-369. https://doi.org/10.1016/B978-085709-5237.00012-8.

Kabanov, B., Burstein, R. and Frumkin A. (1947). Pitting corrosion of metals - corrosion Discuss, Faraday Soc. NI. 254,12-26.

Kadhim, M. G., \& Albdiry, M. (2017). A critical review on corrosion and its prevention in the oilfield equipment. Journal of Petroleum Research and Study, 162-189.

Kolotyrkin A. M. (2013). Pitting Corrosion of Metals. Corrosion, 19(8), 261-268. https://doi.org/10.5006/0010-931219.8.261

Kolotyrkin, J. M. (1963). Pitting corrosion of metals. Corrosion, 19(8). https://doi.org/10.5006/0010-9312-19.8.261

Kolotyrkin, M., \& Golovina, G.V. (1963). Pitting corrosion of metal, Acad. Sci. U.S.S.R. 148(106).

Kumar, M., Kant, S., \& Kumar, S., (2019). Corrosion behavior of wire arc sprayed Ni-based coatings in extreme environment. Materials Research Express, 6, 106427. https://doi.org/10.1088/2053-1591/ab3bd8

Kumar, R., \& Kumar, S. (2018). Comparative Parabolic Rate Constant and Coating Properties of Nickel, Cobalt, Iron and Metal Oxide Based Coating: A Review. I-manager's Journal on Material Sci. 6(1),4556. https://doi.org/10.26634/jms.6.1.14379.

Kumar, R., \& Kumar, S. (2018). Thermal Spray Coating Process: A Study. International Journal of Engineering Science and Research Technology, 7(3), 610-617.

Kumar, R., Kumar, R., \& Kumar, S. (2018). Erosion corrosion study of HVOF sprayed thermal sprayed coating on boiler tubes: a review. IJSMS. 1(3), 1-6.

Kumar, R., Singh, R., \& Kumar, S. (2018). Erosion and hot corrosion phenomena in thermal power plant and their preventive methods: a study. Asian Journal of Mechanical Engineering, 7(1), 38-45.

Kumar, S., Kumar, M., \& Handa, A. (2019). High temperature oxidation and erosion-corrosion behaviour of wire arc sprayed Ni-Cr coating on boiler steel. Material Research Express. 6, 125533. https://doi.org/10.1088/20531591/ab5fae.

Kumar, S., Kumar, M., \& Handa, A. (2018). Combating hot corrosion of boiler tubes- a study. Journal of Engineering Failure Analysis, 94, 379-395. https://doi.org/10.1016/j.engfailanal.2018.08.004

Kumar, S., Kumar, M., \& Handa, A., (2019). comparative study of high temperature oxidation behavior of wire arc sprayed Ni-Cr and Ni-Al coatings. Engineering Failure Analysis, 106, 104173 -104189.

Kumar, S., Kumar, R., Singh, S., Singh, H., \& Handa, A. (2020). The role of thermal spray coating to combat hot corrosion of boiler tubes: a study. Journal of Xidian University, 14(5), 229-239. https://doi.org/10.37896/jxu14.5/024.

Levy, A. V. (1995). Erosion and erosion-corrosion of metals. Corrosion, 51(11), 872-883. https://doi.org/10.5006/1.3293564.

Lynch, R. F. (2001). Zinc: Alloying, Thermo-mechanical Processing, Properties, and Applications. Encyclopedia of Materials: Science and Technology (Second Edition), 9869-9883. https://doi.org/10.1016/B0-08-043152-6/01786-1

Makhlouf, A. S. H. (2015). Chapter 15 - intelligent stannate-based coatings of self-healing functionality for magnesium alloys, Intelligent Coatings for Corrosion Control, Butterworth-Heinemann, 537-555, ISBN 9780124114678, https://doi.org/10.1016/B978-0-12-411467-8.00015-5.

Martinchek, G. A., \& Max, R. (2000). Detection of pitting corrosion. United States Patent. 6015484

Michael, E., \& Pudji, P. (1996). Standard handbook of petroleum and natural gas engineering. Production Engineering, 2.

North, N. A., \& Macleod, I. (1987). Corrosion of metals. Conservation of Marine Archaeological Objects, 68-98.

Obrecht, M. F., \& Pourbaix, M. (1967). Corrosion of metals in potable water systems. Journal - American Water Works Association, 59(8), 977-992. doi:10.1002/j.1551-8833.1967.tb03436.x 
Palanisamy, G. (2019). Corrosion inhibitors. Open access peer reviewed chapter, 44-53. doi: //doi.org/10.1016/j.engfailanal.2018.08.004

Popov, B. N. and Kumaraguru, S. P. (2012). 25 - Cathodic protection of pipelines, handbook of environmental degradation of materials (Second Edition), William Andrew Publishing, 771-798, https://doi.org/10.1016/B978-14377-3455-3.00025-0.

Popova, T. I., \& Kabanov, B.N. (1961). Pitting Corrosion of metal. J. Phys. Chem. 35(1296), 45-49.

Prawoto, Y., \& Ibrahim K. M. (2009). Effect of ph and chloride concentration on the corrosion of duplex stainless steel. Arabian Journal for Science and Engineering, 34(2), 19-32.

Prutton, C. F., \& Frey, D.R. (2016). Corrosion of metals by organic acids in hydrocarbon solvents. Ind. Eng. Chem. 37, 1, 90-100. https://doi.org/10.1021/ie50421a020

Qian, Y., \& Fang Y. (2015). The application of anti-corrosion coating for preserving the value of equipment asset in chloride-laden environments: A Review. Int. J. Electrochem. Sci. 10, 10756-10780.

Sahoo, P., \& Davim, P. (2017). Comprehensive materials finishing. Surface Finish Coatings, 3, 38-55. https://doi.org/10.1016/B978-0-12-803581-8.09167-0

Sharma, V., Kumar, S., Kumar, M., \& Deepak, D. (2019). High temperature oxidation performance of Ni-Cr-Ti and Ni5Al coatings. Material Today Proceeding, ICFMST-2019, International Conference at Chandigarh University https://doi.org/10.1016/j.matpr.2019.11.048

Shi, X., Avci, R., Geiser, M., and Lewandowski, Z. (2003). Comparative study in chemistry of microbially and electrochemically induced pitting of 316L stainless steel. Corrosion Science, 45, 2577-2595.

Shibli, S. M. A., \& Meena, B. N. (2015). A review on recent approaches in the field of hot dip zinc galvanizing process. Surface and Coatings Tech., doi: 10.1016/j.surfcoat.2014.12.054

Singh, D. D. N. (1995). Various forms of water side corrosion: Causes and prevention. National Workshop on Boiler Corrosion, 16-23.

Tan, Y. J. (2011). Experimental methods designed for measuring corrosion in highly resistive and inhomogeneous media. Corrosion Science. 53, 1145-1155.

Tan, Y. J., Bailey, S., \& Kinsella, B. (2001). Mapping non-uniform corrosion using the wire beam electrode method. II. Crevice corrosion and crevice corrosion exemption. Corrosion Science, 43, 1919-1929.

Vaniukova, L. V., \& Kabanov, B. N. (1948). Pitting corrosion of metal. Proc. Acad. Sci. U.S.S.R. 59, 917-922.

Vedavyasan, C. V. (2013) Corrosion. In: Drioli E., Giorno L. (eds) Encyclopedia of Membranes. Springer, Berlin, Heidelberg. https://sci-hub.se/https://doi.org/10.1007/978-3-642-40872-4_785-3

Zhang, W., \& Frankel S. (2007). Transitions between pitting and intergranular corrosion in AA2024. Electrochimica Acta. 48(9), 1193-1210. doi: 10.1016/S0013-4686(02)00828-9

\section{S. Harsimran}

Department of Computer Science Engineering, CGC,

College of Engineering Landran,

Mohali, Punjab, India.

imharsimran10singh@gmail.com

\section{K. Santosh}

Assistant Professor, Department of

Mechanical Engineering,

Chandigarh Group of College,

Landran, Mohali, Punjab.

santoshdgc@gmail.com

\section{K. Rakesh}

Assistant Professor, Department of

Mechanical Engineering,

Chandigarh Group of College,

Landran, Mohali, Punjab. rk05691@gmail.com 